\title{
Factors associated with impairments in new leprosy patients: the AMFES cohort
}

\author{
A. MEIMA ${ }^{+}$, P. R. SAUNDERSON*, S. GEBRE*, \\ K. DESTA*, G. J. VAN OORTMARSSEN ${ }^{+} \&$ \\ J.D.F. HABBEMA ${ }^{+}$ \\ ${ }^{+}$Department of Public Health, Erasmus University Rotterdam, The \\ Netherlands \\ *All Africa Leprosy, Tuberculosis and Rehabilitation Centre, Addis \\ Ababa, Ethiopia
}

\section{Accepted for publication 28 April 1999}

\begin{abstract}
Summary Data on the importance of the delay between onset of symptoms and registration as a risk factor for impairment are sparse. This study investigates the quantitative relationship between this delay, other risk factors and the impairment status in new leprosy patients. It reports on 592 new leprosy patients enrolled in 19881992 in the prospective ALERT MDT Field Evaluation Study in central Ethiopia (AMFES). The influence of the risk factors sex, age, delay, $\mathrm{PB} / \mathrm{MB}$ classification in relation to $\mathrm{BI}$, and prior dapsone treatment on the impairment status at intake is analysed. Estimates for the delay are based on patient recall. For the risk factors, odds ratios on impairment and on severity of impairment were calculated using both univariate and multivariate logistic regression. The registration delay was 2 years or more for $44 \%$ of new patients. The prevalence of impairment (WHO impairment grades 1 and 2 combined) increased continuously from $36 \%$ for new patients with a delay of $0-1$ year to $81 \%$ for new patients with delays of 4 years or more. This prevalence also increased continuously with age; it rose from $26 \%$ in children to $80 \%$ for the age group 60 and over. In the multivariate regression, the odds ratios for new patients to be impaired were statistically significant for all delay categories (baseline 1-2 years) and age groups (baseline 15-29 years). No statistically significant differences in odds ratios were observed with respect to sex and $\mathrm{PB} / \mathrm{MB}$ classification in relation to BI. Overall, $31 \%$ of new patients presented with WHO impairment grade 1 and $23 \%$ with grade 2 . The risk on grade 2 also increased with the registration delay amongst the impaired new patients. Relatively few impaired males and relatively few impaired MB patients with a $\mathrm{BI}$ value of 3 or higher had grade 2 impairment. Registration delay and age are the main risk factors for presentation with impairment. Reduction of delay in central Ethiopia requires re-thinking of control methodologies. The search for ways to reduce delays in diagnosis and treatment should receive high priority in leprosy research and in leprosy control programmes.
\end{abstract}

Correspondence to: Abraham Meima, M.Sc., Department of Public Health, Faculty of Medicine and Health Sciences, Erasmus University Rotterdam, PO Box 1738, 3000 DR Rotterdam, The Netherlands. Fax: +31 104089449 ; e-mail: Meima@mgz.fgg.eur.nl 


\section{Introduction}

The implementation of effective antibacterial treatment for leprosy has shifted the focus in leprosy programmes to prevention of disability. However, many new cases already have impairments and disabilities. Amongst major endemic countries, the proportion of new cases presenting with WHO disability grade 2 was reported in 1995 to range from $6 \%$ to $21 \%$. ' Several studies showed that the majority of patients who were impaired at release from MDT already had nerve function impairment at the time of registration. $^{2-4}$ This paper documents risk factors for impairment in new cases, which may contribute to the improvement of prevention of disability activities in leprosy control programmes.

Various factors might be associated with the presence of impairment at registration. For example, differences in impairment status at registration have been observed with respect to gender, age at registration, and leprosy type according to clinical classification systems or the WHO paucibacillary/multibacillary (PB/MB) classification. ${ }^{2-9}$ At the same time, higher proportions of MB cases amongst male patients have been documented, ${ }^{2,7-10}$ and different age distributions for new PB and MB cases have been reported. ${ }^{911-14}$ This implies that interrelations must be taken into account when analysing which factors are associated with the impairment status at registration.

In addition, it is generally believed that a longer delay between onset of disease and registration, here called registration delay, is associated with more impairment. The proportion of new cases with impairments at registration is, for instance, much higher in passively, as compared to actively, detected cases in Malawi. ${ }^{2}$ Richardus et al. ${ }^{3}$ concluded that early diagnosis (and subsequent activities for prevention of disability) could prevent impairments in more than $30 \%$ of all patients in a control programme in Bangladesh, more than any intervention at a later stage could achieve.

Registration delay has been documented in several studies. ${ }^{7,8,10,15-22}$ A study on long term leprosy trends in Thailand showed that important declines in the registration delay coincided with a declining trend in the proportion of cases presenting with grade 2 disability. ${ }^{17}$ A recent study from another area in Thailand ${ }^{4}$ revealed a highly significant linear trend in the proportion of new cases with grade 2 disability in relation to the registration delay. Bekri et al. ${ }^{22}$ concluded that the median registration delay was more than twice as high in disabled as compared with non-disabled patients from Ethiopia. Wittenhorst et $a .^{7}$ found a highly significant association between registration delay and presence of impairments in new leprosy patients from Zimbabwe. It is beyond doubt that the presence and severity of impairments are associated with duration of disease (e.g. ${ }^{23-27}$ ). Surprisingly, knowledge on the quantitative relationship between the registration delay and the impairment status at registration in new leprosy patients-while simultaneously considering the impact of other, interrelated factors - is very limited.

This paper therefore examines the impairment status at registration as a function of several potential risk factors and their interaction for patients who were enrolled in a longterm prospective study of the effectiveness of the WHO-recommended MDT regimens under routine leprosy control service conditions. This study, the ALERT MDT Field Evaluation Study (AMFES), is carried out in a selected area within ALERT's leprosy control programme in central Ethiopia. Details of the design of the AMFES study and preliminary results for the new patients who were registered in the first 3 years have been reported upon before. $^{28,29}$ 


\section{Materials and methods}

Case-finding in ALERT's control programme was almost exclusively passive. All new cases from the selected area were eligible for AMFES, but not all patients presenting during the intake period were enrolled, mainly because of limitations in the accessibility of leprosy clinics. The AMFES intake period was April 1988 to March 1993.

Cases who were relapses from previous chemotherapy treatment and newly detected cases with errors in diagnosis or in enrolment procedures were excluded from the present study. The present study involves all remaining newly detected cases who were enrolled in the AMFES study. Patient characteristics included are age, sex, classification, bacteriological index $(\mathrm{BI})$, duration of prior dapsone treatment, impairment status and registration delay. $\mathrm{PB}$ and MB patients who received no more than 4 weeks and no more than 16 weeks of dapsone, respectively, were regarded as 'new, untreated', and were included in the study. Impairments are in this paper expressed in terms of the 'WHO disability grades' and are, following Reed et al. ${ }^{30}$ referred to as 'WHO impairment grades'.

The type of treatment (PB or $\mathrm{MB}$ ) was chosen on the basis of clinical classification and skin smears. Skin smears were routinely taken from both earlobes and from at least two skin lesions for all patients, and were repeated after 4 or 8 weeks in case of doubt. For some patients, the smear was either not done, or the result was not available for logistic reasons. For clinical classification, the simplified system for field workers recommended by Jopling ${ }^{31}$ (which adds B B to the BL group) was used. Tuberculoid (TT) and borderline-tuberculoid (BT) patients with a negative smear at all sites were normally given PB treatment. Until July 1989, BT patients with BI not exceeding 1 were included in the PB group. Borderlinelepromatous (BL) and lepromatous (LL) patients and those with a positive smear at one or more sites were given $\mathrm{MB}$ treatment. For patients with nerve involvement only, lacking skin lesions and whose skin smears were (repeatedly) negative (neural leprosy, NL), assignment of treatment regimen was based on the extent of nerve involvement or on the finding of acidfast bacilli in a nerve biopsy. In case of any controversy, patients were referred to the AMFES medical officer. In practical terms, many patients correctly classified as PB within this study, would be classified as MB if now used criteria focussing on number of skin lesions or number of body areas affected had been applied. ${ }^{32}$ The assignment of treatment regimen was straightforward for most patients. More detailed information on procedures for diagnosis, classification and treatment is given by de Rijk et al. ${ }^{29}$

The registration delay was based on patient recall. Health workers first asked what the patient's complaint was, and then tried to find out when any symptoms (e.g. skin lesions, neurological problems, weakness or numbness in hands and feet) were first noticed, relating them to known events if necessary. The health worker recorded the calendar year of the first notice of symptoms, and the registration delay was calculated from the mid-year of this calendar year and the date of registration. For example, a patient who registered on March 5, 1992 and who recalled having first noticed symptoms in 1990 was assigned a registration delay of 1 year and 8 months. In the Results, we have denoted this as 1-2 years; this category includes all calculated delays between 1.0 and 2.0 years. If this patient had registered on September 5, 1992, he would have been assigned a delay of 2-3 years. Individuals registering in the same year as or before July 1 of the year following the year in which symptoms were first noticed, were assigned a delay of $0-1$ year (i.e. less than 1 year).

The factors associated with increased risk for impairments at the time of registration were analysed both separately and in combination. In the data analysis, odds ratios for risk 
factors for presentation with impairments at the time of registration were calculated using univariate and multivariate logistic regression. Statistical significance refers to the $5 \%$ level. The data analysis was carried out in SPSS.

\section{Results}

A total of 603 new cases were enrolled in the AMFES project. Out of these, four individuals were wrongly diagnosed as having leprosy, and seven had improper enrolment procedures. Thus, 11 new cases had to be excluded from the present data analysis. This paper reports on the resulting 592 newly detected patients.

PROFILE OF AMFES AND ALERT PATIENTS

The 592 included patients and the new cases detected in the same period by ALERT's routine control programme ${ }^{33}$ were compared for age, sex, classification and WHO impairment status. Important discrepancies were not observed, and the patients involved in this study are thus considered to be sufficiently representative for new case detection by ALERT in the same period.

Out of the patients involved in this study, 92\% reported voluntarily. This confirms the passive nature of case finding by ALERT's control programme in the late 1980s and early 1990s. Table 1 shows that the number of males in the study population was almost twice as high as the number of females (male:female ratio: 1.8 ). The child proportion was $14 \%$, and for approximately half of the patients the age at registration was between 15 and 34 years. The most common clinical classifications were BT and BL. TT and NL cases were rarely seen. Skin smears were taken from all but 14 (13 BT and one BL) patients. None of the TT, and 13 B T patients had positive smears ( 10 with BI 1 and three with B I 2). Forty BL patients had a BI of 1 or 2 , and 132 had a BI of 3 or more. The BI was 3 or more for all 84 LL patients but two. Overall, almost half of the patients were smear positive, and more than one third of the patients had high bacterial loads $(\mathrm{BI} \geq 3)$. The group of patients who received $\mathrm{MB}$ treatment consisted of two NL patients, 12 BT patients (including nine smear-positives with two with BI 2), and all BL and LL patients. Overall, almost equal numbers of patients received PB and MB treatment. For data analysis, patients were re-classified according to a composite classification with four categories (PB; $\mathrm{MB}: \mathrm{BI}=0 ; \mathrm{MB}: \mathrm{BI}=1+2$; and $\mathrm{MB}$ : $\mathrm{BI}=3+4+5+6)$. At intake, about $16 \%$ of patients had received dapsone treatment (39 $\mathrm{PB}$ for at most 4 weeks and $54 \mathrm{MB}$ for at most 16 weeks). The registration delay was above 2 years for $44 \%$ of the patients. The mean registration delays for males and females were 2.4 and 2.3 years. Figure 1 presents a frequency distribution of the registration delay. Leprosy induced impairments are very common in the study population: $31 \%$ of new patients presented with grade 1 impairment and $23 \%$ with grade 2.

UNIVARIATE ANALYSIS OF RISK FACTORS FOR PRESENTATION WITH IMPAIRMENT

Table 2 gives details on risk factors for presentation with any impairment (either grade 1 or grade 2). The six cases without information on the registration delay were excluded from the analysis. The univariate results indicate that the risk for presentation with impairment 
Table 1. Characteristics of new patients at intake. Percentages are given in proportion to the numbers of patients for which information is available. Numbers of patients for which information is available are given in brackets if information is not available for all newly detected patients

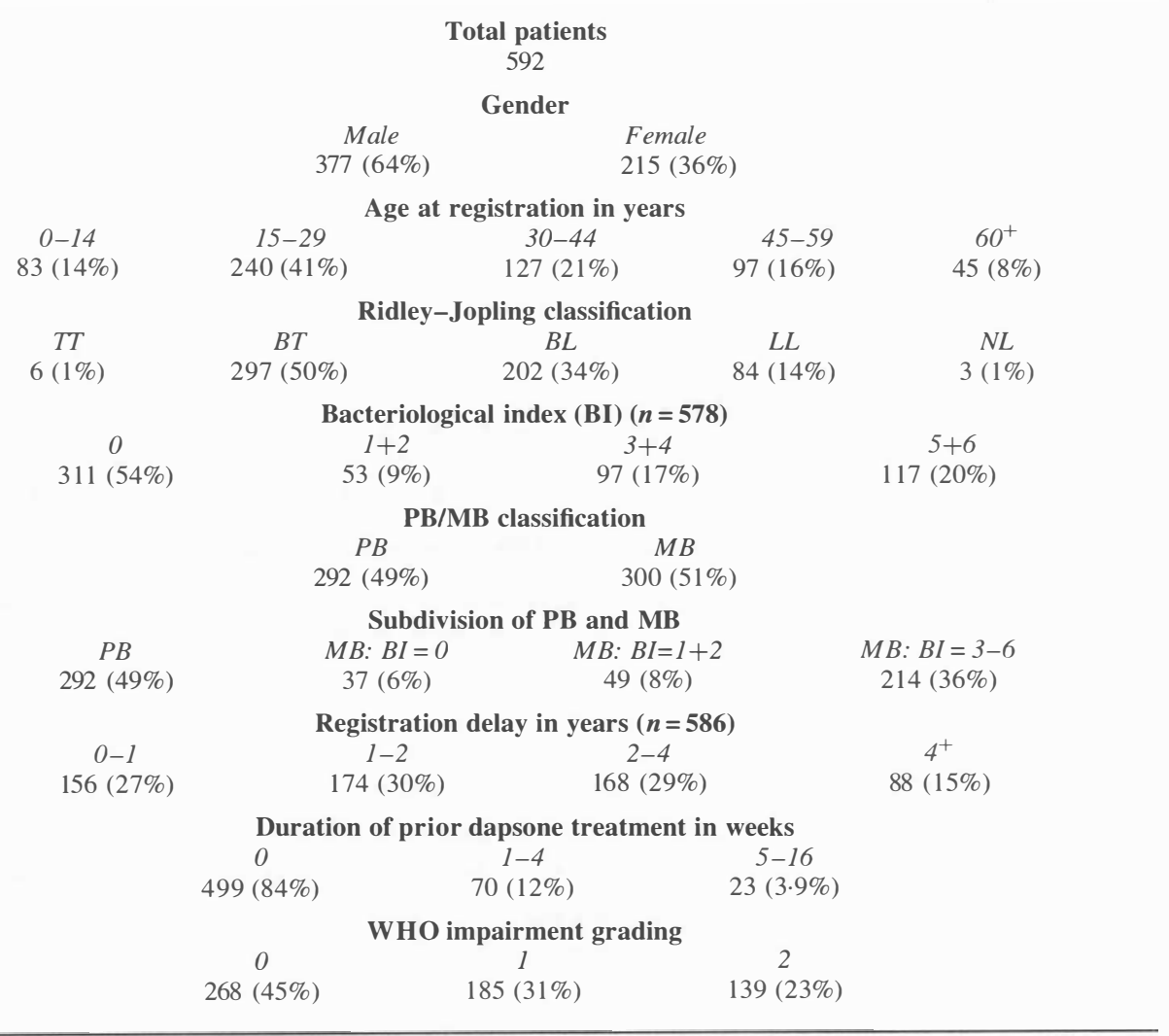

strongly increased with both age and registration delay. The proportion with impairment was much smaller for delays below 2 years than for longer delays (42 versus $72 \%$ ). The overall associations between presence of impairment and age and between presence of impairment and delay were both highly significant $(p<0 \cdot 001)$. A strong association was also found between risk for any impairment and classification in relation to $\mathrm{BI}(p=0.002)$; the risk was highest for $\mathrm{MB}$ patients presenting with $\mathrm{BI} 0,1$ or 2 . Males more of ten presented with impairments than females, but the association was not significant $(p=0 \cdot 07)$. Short term prior dapsone treatment is associated with a higher but non-significant risk of being impaired at the start of MDT treatment $(p=0 \cdot 17)$. The higher risk is even not significant when comparing no prior dapsone treatment with prior dapsone treatment up to a maximum of 16 weeks (i.e. prior durations of treatment of 1-4 weeks and of 5-16 weeks are combined, $p=0 \cdot 09$ ).

Figure 2 illustrates the simultaneous impact of registration delay and other risk factors on 


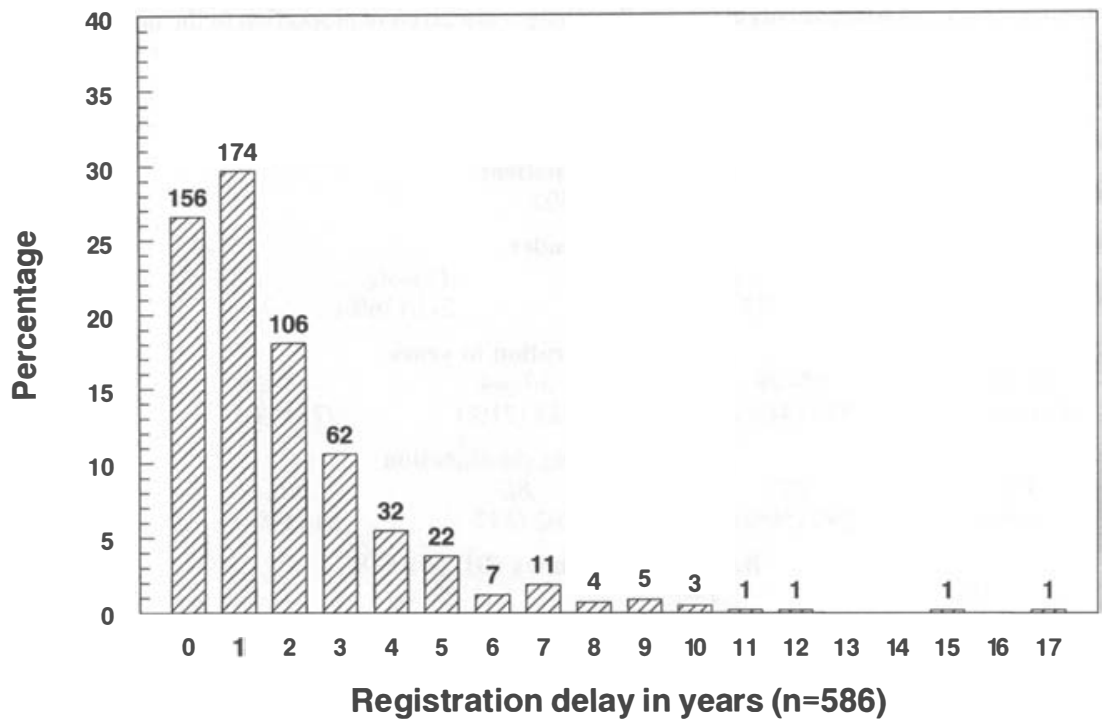

Figure 1. Frequency distribution of the registration delay. Numbers of patients for the respective registration delays are given on top of the bars. Years are truncated, e.g. 2 years means between $2 \cdot 0$ and $3 \cdot 0$ years.

impairment. With increasing delay the proportion presenting with impairment increases in both males and females, in each age group, and in PB and MB patients irrespective of BI. Only $15 \%$ (four out of 27 ) MB patients with BI 0 and with a delay of 1 year or more presented without impairment. Age influences impairment independently of the registration delay: the proportion with impairment increases with age for all registration delays. An effect of MB in relation to $\mathrm{BI}$ on impairment which is independent of the registration delay does not come out clearly.

Table 2 gives the results of multivariate logistic regression for a model with all risk factors included. The odds ratios for the significant risk factors in the univariate analysis are pulled towards the no influence value of 1 in the multivariate logistic regression. Details below refer to the multivariate logistic regression. A statistically significant increase in odds ratios is found both for delay and for age. None of the odds ratios for the other risk factors is significant. In particular, the odds ratios for BI 0 and for BI $1+2$ have lost their category-wise statistical significance in the multivariate regression; however the differences in risk for the factor classification in relation to $\mathrm{BI}$, with relatively higher risks for $\mathrm{MB}$ with $\mathrm{BI} 0$ and $\mathrm{MB}$ with $\mathrm{BI} 1$ or 2 , are overall significant $(p=0.04)$. The model which includes all risk factors was compared with a multivariate model that was obtained by backward selection of risk factors on the basis of the Wald statistic. Little difference was observed: the odds ratios and confidence intervals for the risk factors included in the model obtained by backward selection (age, registration delay and classification in relation to $\mathrm{BI}$ ) are very close to those presented in Table 2.

LEVEL OF IMPAIRMENT

Table 3 gives the results of univariate analysis for the risk for impaired new cases to have 
Table 2. Impairment at intake according to various risk factors with odds ratios for presentation with impairment obtained by univariate and multivariate regression for the 586 new cases with known registration delay

\begin{tabular}{|c|c|c|c|}
\hline Risk factor & $\begin{array}{l}\text { No. impaired } \\
\text { (\% of all cases) }\end{array}$ & $\begin{array}{l}\text { Univariate odds ratio } \\
\text { (95\% confidence interval) }\end{array}$ & $\begin{array}{l}\text { Multivariate odds ratio } \\
\text { (95\% confidence interval) }\end{array}$ \\
\hline \multicolumn{4}{|l|}{ Gender } \\
\hline Male & $215 / 372(58 \%)$ & Baseline & Baseline \\
\hline Female & $107 / 214(50 \%)$ & $0 \cdot 7(0 \cdot 5-1 \cdot 0)$ & $0 \cdot 8(0 \cdot 6-1 \cdot 2)$ \\
\hline \multicolumn{4}{|c|}{ Classification i.r.t. BI } \\
\hline $\mathrm{PB}$ & $150 / 286(52 \%)$ & Baseline & Baseline \\
\hline MB: $\mathrm{BI}=0$ & $28 / 37(76 \%)$ & $2 \cdot 8(1 \cdot 3-6 \cdot 2)$ & $2 \cdot 2(0 \cdot 9-5 \cdot 3)$ \\
\hline MB: $\mathrm{BI}=1+2$ & $35 / 49(71 \%)$ & $2 \cdot 3(1 \cdot 2-4 \cdot 4)$ & $1 \cdot 6(0 \cdot 8-3 \cdot 2)$ \\
\hline $\mathrm{MB}: \mathrm{BI}=3-6$ & $109 / 214(51 \%)$ & $0.9(0.7-1.3)$ & $0.8(0.5-1 \cdot 2)$ \\
\hline \multicolumn{4}{|l|}{ Age (in years) } \\
\hline $0-14$ & $21 / 81(26 \%)$ & $0.4(0.2-0 \cdot 7)$ & $0.4(0.2-0 \cdot 7)$ \\
\hline $15-29$ & $112 / 238(47 \%)$ & Baseline & Baseline \\
\hline $30-44$ & $85 / 127(67 \%)$ & $2 \cdot 3(1 \cdot 5-3 \cdot 6)$ & $1.9(1 \cdot 2-3 \cdot 0)$ \\
\hline $45-59$ & $69 / 96(72 \%)$ & $2.9(1.7-4.8)$ & $2 \cdot 6(1 \cdot 5-4 \cdot 5)$ \\
\hline $60+$ & $35 / 44(80 \%)$ & $4 \cdot 4(2 \cdot 0-9 \cdot 5)$ & $4 \cdot 2(1 \cdot 8-9 \cdot 6)$ \\
\hline \multicolumn{4}{|c|}{ Registration delay (years) } \\
\hline $0-1$ & $56 / 156(36 \%)$ & $0 \cdot 6(0 \cdot 4-1 \cdot 0)$ & $0 \cdot 6(0 \cdot 4-1 \cdot 0)$ \\
\hline $1-2$ & $82 / 174(47 \%)$ & Baseline & Baseline \\
\hline $2-4$ & $113 / 168(67 \%)$ & $2 \cdot 3(1 \cdot 5-3 \cdot 6)$ & $2 \cdot 1(1 \cdot 3-3 \cdot 4)$ \\
\hline $4+$ & $71 / 88(81 \%)$ & $4 \cdot 7(2 \cdot 6-8 \cdot 6)$ & $4 \cdot 5(2 \cdot 3-8 \cdot 5)$ \\
\hline \multicolumn{4}{|c|}{ Prior dapsone treatment (weeks) } \\
\hline None & $264 / 494(53 \%)$ & Baseline & Baseline \\
\hline $1-4$ & $42 / 69(61 \%)$ & $1 \cdot 4(0 \cdot 8-2 \cdot 3)$ & $1.0(0.6-1.9)$ \\
\hline $5-16$ & $16 / 23(70 \%)$ & $2 \cdot 0(0 \cdot 8-4.9)$ & $2 \cdot 5(0.9-6.9)$ \\
\hline
\end{tabular}

grade 2 impairment. The multivariate results are not given, because they hardly differed from the univariate results. The risk is higher for long registration delays, but odds ratios for the longer delays are only just significant. The proportion with grade 2 impairment among impaired cases was $31 \%$ for delays below, and 52\% for delays above 2 years. Figure 3 shows that longer registration delays are particularly associated with a higher proportion of grade 2 impairment. The apparent limited influence of longer delays on the proportion with grade 1 impairment must partially be due to an increase in grade 2 resulting from worsening of grade 1 , which is largely 'compensated' by individuals who were free from impairment but who develop grade 1 with increasing delay.

Other factors show differences with respect to their influence on the risk of any impairment and on the severity of impairment in impaired cases. Firstly, MB with BI 3 or more gives a significantly lower risk for grade 2 impairment (baseline: PB leprosy). Secondly, there is no increase in the risk of grade 2 impairment with age. In fact, the risk appears to be highest for children and lowest for individuals of age 45 and older. No decrease was found in the mean registration delay with age in impaired new cases. Finally, while overall having less impairments, females with impairment more often had grade 2 than impaired males (53 versus $38 \%$ ). Figure 4 shows that the excess in grade 2 impairment in impaired females as compared with impaired males exists for registration delays above 1 year and for all age groups. Gender, age, registration delay and classification in relation to BI were all statistically significant risk factors, but prior dapsone treatment was not. 

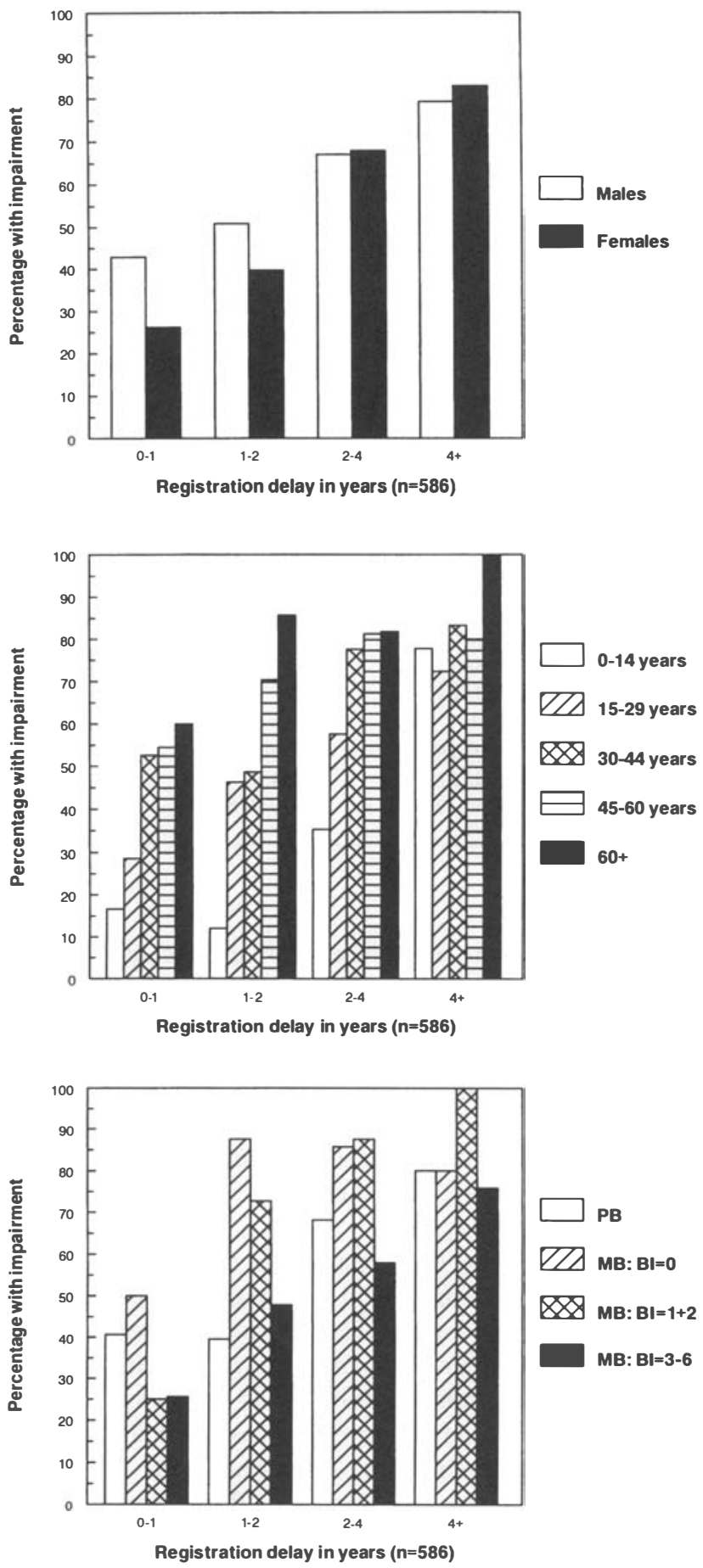

Figure 2. Proportions of new patients presenting with impairment according to registration delay in relation to respectively gender, age, and classification in relation to $\mathrm{BI}$. 
Table 3. Grade 2 versus grade 1 impairment at intake according to various risk factors with odds ratios for presentation with grade 2 impairment obtained by univariate regression for the 322 impaired new cases with known registration delay

\begin{tabular}{|c|c|c|}
\hline Risk factor & $\begin{array}{l}\text { No. with grade } 2 \text { impairment } \\
\text { (\% of all impaired cases) }\end{array}$ & $\begin{array}{l}\text { Univariate odds ratio } \\
\text { (95\% confidence interval) }\end{array}$ \\
\hline \multicolumn{3}{|l|}{ Gender } \\
\hline Male & $82 / 215(38 \%)$ & Baseline \\
\hline Female & $57 / 107(53 \%)$ & $1.8(1.2-3 \cdot 0)$ \\
\hline \multicolumn{3}{|c|}{ Classification i.r.t. BI } \\
\hline $\mathrm{PB}$ & $72 / 150(48 \%)$ & Baseline \\
\hline $\mathrm{MB}: \mathrm{BI}=0$ & $14 / 28(50 \%)$ & $1 \cdot 1(0 \cdot 5-2 \cdot 4)$ \\
\hline $\mathrm{MB}: \mathrm{BI}=1+2$ & $19 / 35(54 \%)$ & $1 \cdot 3(0 \cdot 6-2 \cdot 7)$ \\
\hline $\mathrm{MB}: \mathrm{BI}=3-6$ & $34 / 109(31 \%)$ & $0.5(0 \cdot 3-0 \cdot 8)$ \\
\hline \multicolumn{3}{|l|}{ Age (in years) } \\
\hline $0-14$ & $15 / 21(71 \%)$ & $3 \cdot 5(1 \cdot 2-9 \cdot 6)$ \\
\hline $15-29$ & $47 / 112(42 \%)$ & Baseline \\
\hline $30-44$ & $46 / 85(54 \%)$ & $1 \cdot 6(0 \cdot 9-2 \cdot 9)$ \\
\hline $45-59$ & $19 / 69(28 \%)$ & $0.5(0 \cdot 3-1.0)$ \\
\hline $60+$ & $12 / 35(34 \%)$ & $0 \cdot 7(0 \cdot 3-1 \cdot 6)$ \\
\hline \multicolumn{3}{|c|}{ Registration delay (years) } \\
\hline $0-1$ & $16 / 56(29 \%)$ & $0 \cdot 8(0.4-1.7)$ \\
\hline $1-2$ & $27 / 82(33 \%)$ & Baseline \\
\hline $2-4$ & $58 / 113(51 \%)$ & $2 \cdot 1(1 \cdot 2-3 \cdot 9)$ \\
\hline $4+$ & $38 / 71(54 \%)$ & $2 \cdot 3(1 \cdot 2-4 \cdot 5)$ \\
\hline \multicolumn{3}{|c|}{ Prior dapsone treatment (weeks) } \\
\hline None & $116 / 264(44 \%)$ & Baseline \\
\hline $1-4$ & $17 / 42(40 \%)$ & $0.9(0.4-1.7)$ \\
\hline $5-16$ & $6 / 16(38 \%)$ & $0 \cdot 8(0 \cdot 3-2 \cdot 2)$ \\
\hline
\end{tabular}

\section{Discussion}

The objective of this study was to examine the impairment status at registration as a function of registration delay, age, classification in relation to BI, gender and prior short term dapsone treatment.

\section{RISK FACTOR: DELAY IN REGISTRATION}

This study clearly shows a heavy impact of long registration delay on the impairment status of new leprosy patients from central Ethiopia. Patients with delays of less than 2 years had a much smaller chance $(42 \%)$ of being impaired than patients with longer delays $(72 \%)$. Among the impaired, similar differences were observed: their chance of grade 2 impairment was $31 \%$ for delays below and $52 \%$ for delays above 2 years.

The role of registration delay was also addressed in recent studies from Zimbabwe and Thailand. A strong association between delay and grade 2 impairment was shown in the study from Zimbabwe. ${ }^{7}$ Further analysis of the dataset underlying that study revealed that $41 \%$ of patients with a registration delay below 2 years presented with impairment against $60 \%$ of patients with longer delays. The proportion with grade 2 impairment among the impaired new patients from Zimbabwe increased from $60 \%$ for delays below 2 years to $73 \%$ for delays above 2 years. 


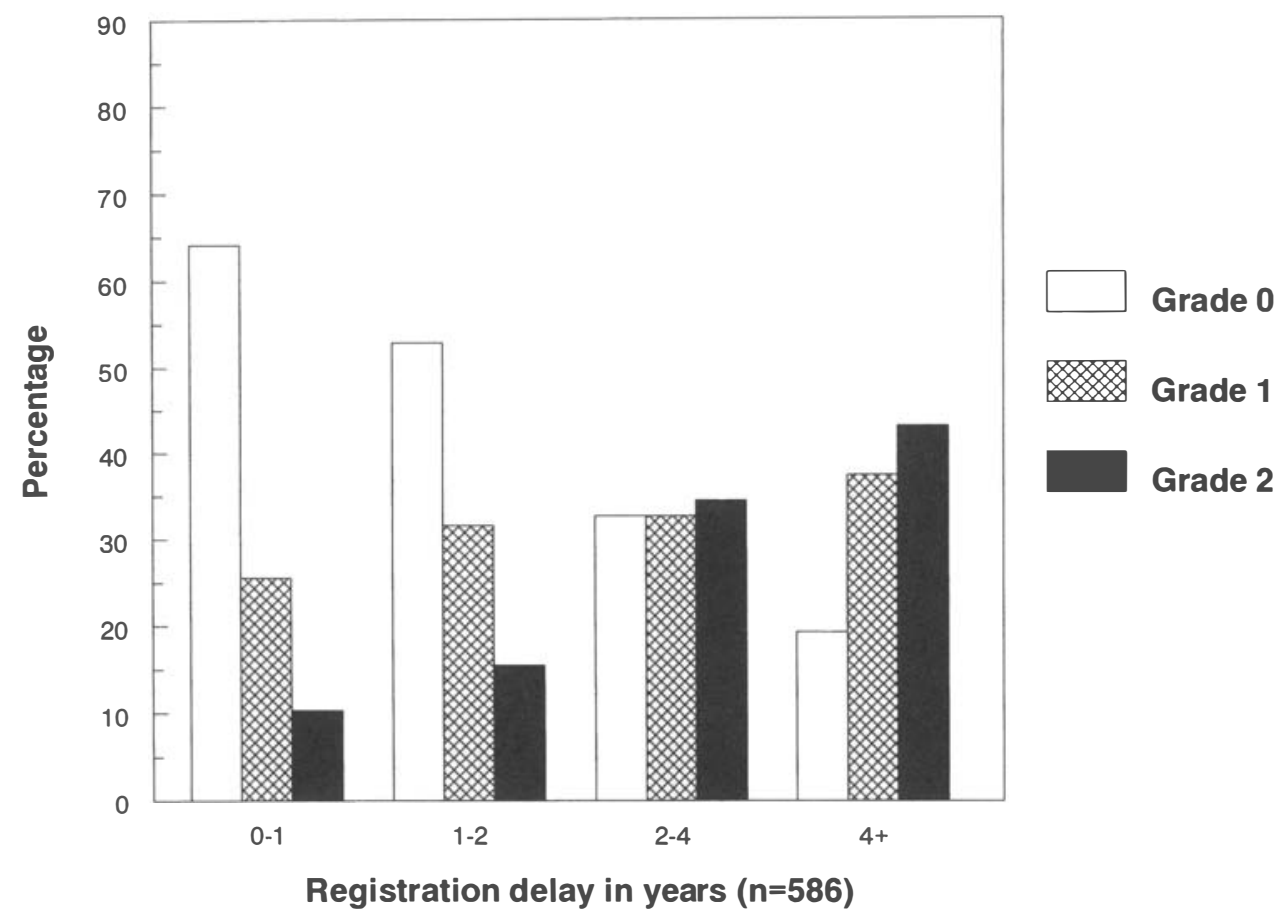

Figure 3. Impairment status of new leprosy patients according to registration delay.

For Thailand ${ }^{4}$ also, a significant association with delay was found: $17 \%$ of patients with a delay below 2 years had impairments against $23 \%$ of patients with longer delays. The association between delay and the proportion grade 2 impairment amongst the impaired was particularly strong: $30 \%$ for delays below 2 years and $58 \%$ for longer delays had grade 2 . Biological differences between populations and differences in case detection and assessment methods, methods of interviewing patients and calculation procedures may all underlie differences in results from studies on the importance of the registration delay as a risk factor for impairment. Nevertheless, all the above results are remarkably consistent.

\section{RISK FACTOR: AGE}

Several studies have reported that the risk of impairment in new cases increases with age., ${ }^{2,5,7,8}$ However, such a univariate association does not occur in the study from Thailand, ${ }^{4}$ and observed univariate associations between age and impairment may be confounded by the registration delay. In the present study, the multivariate analysis shows that the risk of impairment increases with age independently of other risk factors including registration delay. Interestingly, a different effect of age was shown for the risk of grade 2 impairment amongst impaired new cases: this study showed this risk to be lowest among the individuals of ages 45 and above. We do not have a straightforward explanation for these age effects. Additional examination of the data presented in the Thailand study ${ }^{4}$ and of the data sets underlying the Zimbabwe study ${ }^{7}$ and another recent study from Bangladesh ${ }^{9}$ did not give further evidence for the finding of a lower risk of grade 2 impairment in impaired new cases of older ages. 
Impairments in new leprosy patients

199
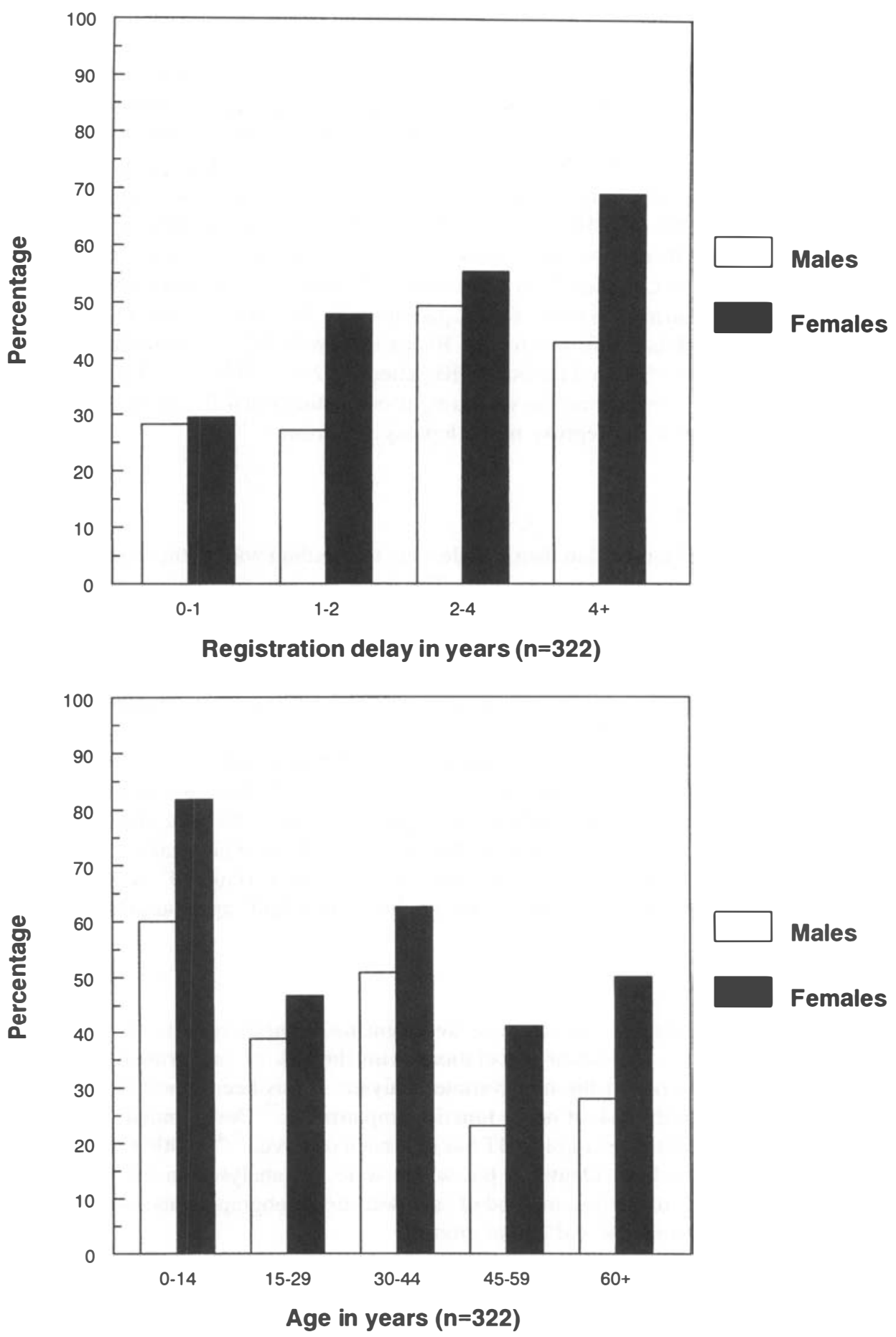

Figure 4. Proportion of impaired new leprosy patients presenting with grade 2 impairment according to gender in relation to both registration delay and age. 
RISK FACTOR: CLASSIFICATION IN RELATION TO BI

MB patients with B I 0, 1 or 2 had the highest risks of impairment. The lower odds ratios in the multivariate analysis are largely explained by the relatively high age of these MB patients. MB patients with high bacterial loads $(\mathrm{BI} \geq 3$ ) had relatively few impairments, and had a significantly lower risk of grade 2 once being impaired. Further investigation showed that this risk was significantly lower only for LL patients with $\mathrm{BI} \geq 3$ in univariate analysis, and for both $\mathrm{BL}$ and $\mathrm{LL}$ patients with $\mathrm{BI} \geq 3$ in multivariate analysis. In the present study, all LL patients but two had a BI of 3 or more. Gilbody stated that borderline leprosy is 'potentially the most widespread and crippling form of leprosy'. ${ }^{34}$ This is in line with our observation that the risk of grade 2 impairment is lower for LL patients with BI 3 or more, but does not explain our finding that the risk is also lower for the BL patients with BI 3 or more than for the PB patients (all but seven are BT) and the other MB patients (12 BT, 70 BL, two LL and two NL). This finding, however, may not be too surprising if one realizes that BL leprosy with BI 3 or more is very close to true LL leprosy in the leprosy spectrum.

\section{RISK FACTOR: GENDER}

Males had impairments more of ten than females, but this finding was neither significant in the univariate nor in the multivariate analysis. The mean registration delays for males and females were almost identical ( 2.4 versus 2.3 years). The finding as such that impairments are more common in males than females (although with a non-significant difference) is in line with many reports in literature (e.g. ${ }^{2,4,5,8,9,18}$ ). The data underlying the study from Zimbabwe $^{7}$ not only show a higher risk in males, but also longer mean registration delays for males as compared to females ( $3 \cdot 1$ versus $2 \cdot 1$ years).

A significant excess in grade 2 impairment in impaired females was found in the univariate analysis. This excess is difficult to explain (see also Figure 4), and its significancy disappeared in the multivariate analysis. Comparison with published data ${ }^{4,8}$ and data underlying published reports ${ }^{7,9}$ revealed that the proportion with grade 2 impairment among the impaired was higher in males than females from Thailand ${ }^{4}$ and Zimbabwe, ${ }^{7}$ whereas equal proportions were found for the studies from $\mathrm{Chad}^{8}$ and Bangladesh. ${ }^{9}$

\section{OTHER RISK FACTORS}

In this study, 92 patients received dapsone treatment for a duration of 1-16 weeks before inclusion. In the cohort, significant associations with the risk of impairment were neither found in the univariate nor in the multivariate analyses. It has been reported that dapsone treatment may enhance the risk of nerve function impairment. ${ }^{35}$ Development of new nerve function impairment after the start of MDT has also been observed. ${ }^{3,4,36}$ Other risk factors for impairment which have been identified but which were not analysed in the present study include occupation, site of lesions, method of case detection, geographic and socio-economic factors, educational attainment and ethnic group. ${ }^{6}$

SOURCES OF BIAS

Registration delays are obtained by asking the patient when he or she first noticed symptoms. In his or her mind, a patient might advance this moment in time, especially in cases of long 
duration of disease. On the other hand, patients or staff could presume that the duration of disease is of long duration when impairments are present. Clearly, the fallibility of patient's recall of first awareness of symptoms can bias the relationship between delay and risk of impairment, although it is difficult to judge the direction of the effect.

In the present study, the date of registration was combined with the recorded calendar year of first notice of symptoms in estimating the registration delay. We used the mid-year of this calendar year. This inaccuracy will lead to underestimation of the strength of the association between delay and impairment.

Other sources of bias also cannot be excluded. Case detection was of a passive nature and differences in awareness of symptoms and in self reporting behaviour can exist. Recall of onset of symptoms may also vary between groups of patients. It may be possible that certain findings from this study (in particular the lower risks of grade 2 impairment amongst the impaired in males and in patients of ages 45 and above) are to some extent related to these sources of bias. On the whole, we still found strong associations between impairments status and risk factors in this cohort. Studies comparing routinely obtained registration delays with delays obtained by carefully designed in depth interviews might give valuable information on the reliability of the registration delay.

\section{SIZE OF THE PROBLEM}

Individuals with grade 1 impairment are at risk of developing more severe impairments and subsequent disabilities. This study has shown that short registration delays are associated with less grade 1 impairment. The size of the impairment problem in new cases is usually only expressed in terms of the proportion with grade 2 impairment. In a report from 1995, this proportion was above $20 \%$ in four out of fifteen major endemic countries that together contributed $95 \%$ of the world wide new case load with grade 2 impairment. ${ }^{1}$ From this perspective, the $23 \%$ grade 2 impairment observed in this study is disturbingly high. It is encouraging that the proportion with grade 2 impairment reported by ALERT's control services in central Ethiopia was somewhat lower in 1995, 1996 and 1997 than in the early 1990s. ${ }^{37}$ Considering ALERT's presence in the area for a period of over 3 decades, re-thinking of control methodologies is definitely required, although it is also clear that public attitudes towards leprosy cannot be changed easily. ${ }^{22}$

IMPLICATIONS FOR RESEARCH AND CONTROL

The search for ways to reduce delays in diagnosis and treatment should have high priority in leprosy research and in leprosy control programmes. Research addressing this challenge has recently been conducted in Ethiopia. It was shown that ex-leprosy patients were important advisors for seeking early treatment. Also, 21 out of 31 patients $(68 \%)$ initially presenting with grade 2 impairment versus 11 out of 48 non-impaired patients $(23 \%)$ had first sought help from traditional healers instead of directly contacting the general health services (unpublished data from the All Africa Leprosy, Tuberculosis and Rehabilitation Centre (ALERT), Addis Ababa, Ethiopia).

A second study ${ }^{22}$ broke down the delay until start of treatment into several components. It was shown that just over $50 \%$ of the delay occurs before the patient seeks any help. Use of some form of traditional medicine accounted for just under one-third of the delay, and delay after attending a recognized clinic accounts for over $10 \%$ of the total delay. The delay until 
the patient's first action and the delay between first action and the first visit to a recognized clinic were significantly longer for impaired patients. High levels of stigma and use of traditional medicine were found to be associated with more impairment when comparing two rural areas of Ethiopia with different impairment rates in new patients.

It is highly questionable whether a shift to active methods of case finding can be costeffective. In addition, there is already a tendency to integrate leprosy services into the general health services. This calls for proper management of leprosy suspects, and delays in referral for leprosy treatment within the general health services should require special attention. In view of problems with referral, Bekri et al. ${ }^{22}$ suggest that in the Ethiopian context, it would be ideal for diagnosis and the start of treatment to be done at the rural clinic, with examination by a specialist at a later stage. They also state that reducing stigma is far more complex than imparting knowledge alone, and that health education campaigns must be well planned and sufficiently sophisticated in order to have any impact. A recent review already indicated that gender inequalities should be a point of concern to health services and in health education. ${ }^{38}$ A national advertising programme involving mass media was an integral part of a successful campaign against leprosy in the early 1990s in Sri Lanka. ${ }^{39}$ The potential benefits of well-researched media campaigns need to be investigated.

In conclusion, a better understanding of factors determining delays is of eminent importance for the development of strategies that minimize impairment at registration and thus minimize permanent disability in those who develop leprosy. This has also been recognized by the Medico-Social Commission of ILEP, which identified investigation of factors influencing delay in diagnosis and treatment for different communities as a major research priority in the context of prevention of disability in leprosy (ILEP: Development of an ILEP co-ordinated programme of research on nerve damage and reactions in leprosy. Internal Report. Draft, June 1998).

\section{Acknowledgements}

The authors wish to thank both Dr J. P. Velema and the Danish Bangladesh Leprosy Mission for offering the opportunity to compare findings from this study with datasets from Zimbabwe and Bangladesh. The dedicated work of the staff of the All Africa Leprosy, Tuberculosis and Rehabilitation Training Centre (ALERT) and financial support by the Netherlands Leprosy Relief (NLR) have made it possible to conduct this study and are gratefully acknowledged.

\section{References}

1 World Health Organization. Leprosy disabilities: magnitude of the problem. Wkly Epidemiol Rec 1995; 70: 269275.

2 Ponnighaus IM, Boerrigter G, Fine PE, Ponnighaus JM, Russell J. Disabilities in leprosy patients ascertained in a total population survey in Karonga District, northern Malawi. Lepr Rev 1990; 61: 366-374.

3 Richardus JH, Finlay KM, Croft RP, Smith WC. Nerve function impairment in leprosy at diagnosis and at completion of MDT: a retrospective cohort study of 786 patients in Bangladesh. Lepr Rev 1996; 67: 297-305.

4 Schreuder PA. The occurrence of reactions and impairments in leprosy: experience in the leprosy control program of three provinces in Northeastern Thailand, 1978-1995. III. Neural and other impairments. Int J Lepr Other Mycobact Dis 1998; 66: 170-181.

5 Tiendrebeogo A, Toure I, Zerbo PJ. A survey of leprosy impairments and disabilities among patients treated by MDT in Burkina Faso. Int J Le pr Other Mycobact Dis 1996; 64: 15-25.

6 Ladhani S. Leprosy disabilities: the impact of multidrug therapy (MDT). Int J Dermatol 1997; 36: 561-572. 
${ }^{7}$ Wittenhorst B, Vree ML, Ten Ham PB, Velema JP. The National Leprosy Control Programme of Zimbabwe: a data analysis, 1983-1992. Lepr Rev 1998; 69: 46-56.

8: Schafer J. Leprosy and disability control in the Guera Prefecture of Chad, Africa: do women have access to leprosy control services? Lepr Rev 1998; 69: 267-278.

${ }^{9}$ Richardus JH, Meima A, Croft RP, Habbema JDF. Case detection, gender and disability in leprosy in Bangladesh: a trend analysis. Lepr Rev 1999; 70: 160-173.

10 Schreuder PA. The occurrence of reactions and impairments in leprosy: experience in the leprosy control program of three provinces in Northeastern Thailand, 1978-1995. I. Overview of the study. Int J Lepr Other Mycobact Dis 1998; 66: 149-158.

11 Noordeen SK. Leprosy in Lakshadweep Islands. Lepr India 1976; 48: 244-257.

12 Lechat MF, Vanderveken M. Basic epidemiological indicators for monitoring leprosy control. Tokio: Sasakawa Memorial Health Foundation, 1983.

13 Monchy D, Huerre M, Crouzat M, Dubourdieu D, Duval P, Sottil JP. La lèpre en Nouvelle-Calédonie de 1983 a 1992. Données histopathologiques et épidémiologiques. Bull Soc Pathol Exot 1994; 87: 28-32.

14 Ponnighaus JM, Fine PE, Sterne JA, Bliss L, Wilson RJ, Malema SS, Kileta S. Incidence rates of leprosy in Karonga District, northern Malawi: patterns by age, sex, BCG status and classification. Int J LeprOther Mycobact Dis 1994; 62: 10-23.

15 Li HY, Pan YL, Wang Y. Leprosy control in Shandong Province, China, 1995-1983; some epidemiological features. Int J Lepr Other Mycobact Dis 1985; 53: 79-85.

16 Becx-Bleumink M. Priorities for the future and prospects for leprosy control. Int J Lepr Other Mycobact Dis 1993; 61: $82-101$.

17 Smith TC, Richardus JH. Leprosy trends in northern Thailand: 1951-1990. Southeast Asian J Trop Med Public Health 1993; 24: 3-10.

18 Schipper A, Lubbers WJ, Hogeweg M, De Soldenhoff R. Disabilities of hands, feet and eyes in newly diagnosed leprosy patients in eastern Nepal. Lepr Rev 1994; 65: 239-247.

19 Li HY, Weng XM, Li T, Zheng DY, Mao ZM, Ran SP, Liu FW. Long-term effect of leprosy control in two Prefectures of China, 1955-1993. Int J Lepr Other Mycobact Dis 1995; 63: 213-221.

20 World Health Organization. Progress towards the elimination of leprosy as a public health problem. Part I. Wkly Epidemiol Rec 1995; 70: 177-182.

${ }^{21}$ Rao S, Garole V, Walawalkar S, Khot S, Karandikar N. Gender differentials in the social impact of leprosy. Lepr Rev 1996; 67: 190-199.

22 Bekri W, Gebre S, Mengiste A, Saunderson PR, Zewge S. Delay in presentation and start of treatment in leprosy patients: a case-control study of disabled and non-disabled patients in three different settings in Ethiopia. Int $J$ Lepr Other Mycobact Dis 1998; 66: 1-9.

23 Noorden SK, Srinivasan H. Epidemiology of disability in leprosy. I. A general study of disability among male leprosy patients above fifteen years of age. Int J Lepr Other Mycobact Dis 1966; 34: 159-169.

24 Noorden SK, Srinivasan H. Deformity in leprosy: an epidemiological study. Indian JMedRes 1969; 57: 175-181.

25 Srinivasan H. Changes in epidemiology of deformity in leprosy in a rural area in South India. Indian J Med Res 1982; 76: 795-803.

26 Mishra B, Ramu G, Chauhan VS, Kushwaha SS, Dwivedi MP. Leprosy deformities. I. An epidemiological study in a rural area of Rajasthan. Ind J Lepr 1988; 60: 53-62.

27 Girdhar M, Arora SK, Mohan L, Mukhija RD. Pattern of leprosy disabilities in Gorakhpur (Uttar Pradesh). Ind J Lepr 1989; 61: 503-513.

28 de Rijk AJ, Gabre S, Byass P, Berhanu T. Field evaluation of WHO-MDT of fixed duration, at ALERT, Ethiopia: the AMFES project-II. Reaction and neuritis during and after MDT in PB and MB leprosy patients. Lepr Rev 1994; 65: 320-332.

29 de Rijk AJ, Gabre S, Byass P, Berhanu T. Field evaluation of WHO-MDT of fixed duration at ALERT, Ethiopia: the AMFES project-I. MDT course completion, case-holding and another score for disability grading. Lepr Rev 1994; 65: 305-319.

${ }^{30}$ Reed NK, van Brakel WH, Reed DS. Progress of impairment scores following commencement of chemotherapy in multibacillary leprosy patients. Int J Lepr Other Mycobact Dis 1997; 65: 328-336.

31 Jopling WH. A practical classification of leprosy for filed workers. Lepr Rev 1981; 52: 273-277.

32 WHO Expert Committee on Leprosy. Seventh Report. WHO Technical Report Series No. 874. Geneva: World Health Organization, 1998.

33 All Africa Leprosy, Tuberculosis and Training Rehabilitation Centre (ALERT). Annual Reports 1988, 1989, 1990, 1991, 1992, Addis Ababa, Ethiopia.

34 Gilbody JS. Aspects of rehabilitation in leprosy. Int J Lepr Other Mycobact Dis 1992; 60: 608-640.

35 Gupte MD. Dapsone treatment and deformities. A retrospective study. Lepr India 1979; 51: 218-235.

36 van Brakel WH. Peripheral neuropathy in leprosy. The continuing challenge. Thesis, University of Utrecht, 1994.

37 All Africa Leprosy, Tuberculosis and Training Rehabilitation Centre (ALERT). Annual Report 1997.

38 Le Grand A. Women and leprosy: a review. Lepr Rev 1997; 68: 203-211.

39 Dewapura DR. Leprosy control in Sri Lanka. World Health Forum 1994; 15: 173-174. 